\title{
Management and outcome of bloodstream infections: a prospective survey in I2I French hospitals (SPA-BACT survey)
}

This article was published in the following Dove Press journal: Infection and Drug Resistance

Oliver Robineau,' Jérome Robert, ${ }^{2}$ Christian Rabaud, ${ }^{3}$ JeanPierre Bedos, ${ }^{4}$ Emmanuelle Varon, ${ }^{5}$ Yves Péan, ${ }^{6}$ Rémy Gauzit, ${ }^{7}$ Serge Alfandari ${ }^{8}$

On behalf of the Sociéte de Pathologie Infectieuse de Langue Française (SPILF), the Observatoire National de l'Épidémiologie de la Résistance Bactérienne aux Antibiotiques (ONERBA), and the Surveillance de la Prescription des Antibiotiques (SPA) Group

'Infectious Disease Department, Dron Hospital, Univ Lille, Tourcoing, ${ }^{2}$ Sorbonne University, UPMC Univ Paris 06, CR7, CIMI, Team EI 3 (Bacteriology), Paris, ${ }^{3}$ Infectious Disease Department, Nancy University Hospital, Nancy, ${ }^{4}$ Intensive Care Unit, Henri Mignot Hospital, Le Chesnay, ${ }^{5}$ Bacteriology Laboratory, HEGP, ${ }^{6}$ Observatoire National de L'epidémiologie de la Résistance Bactérienne aux Antibiotiques (OneRBa), ${ }^{7}$ Intensive Care Unit, Cochin Hospital, APHP, Paris, ${ }^{8}$ Intensive Care Unit, Dron Hospital, Tourcoing, France

Correspondence: Serge Alfandari Service de Réanimation et Maladies Infectieuses CH Dron, I 55 Rue du Pdt Coty, 59200

Tourcoing, France

Tel +33 320694492

Fax +33 320694439

Email salfandari@ch-tourcoing.fr

Oliver Robineau

Service Universitaire des Maladies Infectieuses et du Voyageur, Centre Hospitalier Gustave

Dron, 155 rue du Président René Coty, 59200

Tourcoing, France

Tel +33320694848

Fax +33 320694439

Email olivier.robineau82@gmail.com
Background: Bloodstream infections (BSIs) are severe infections that can be community or hospital acquired. Effects of time to appropriate treatment and impact of antimicrobial management team are discussed in terms of outcome of BSI. We sought to evaluate the impact of initial BSI management on short-term mortality.

Patients and methods: A prospective, multicenter survey was conducted in 121 French hospitals. Participants declaring BSI during a 1-month period were included consecutively. Data on patient comorbidities, illness severity, BSI management, and resistance profile of bacterial strains were collected. Predictors of 10-day mortality were identified by multivariate regression for overall BSI, health care-related and hospital-acquired BSI.

Results: We included 1,952 BSIs. More than a third of them were hospital acquired (39\%). Multidrug resistance was identified in $10 \%$ of cases, mainly in health care-related BSI. Empirical therapy and targeted therapy were appropriate for $61 \%$ and $94 \%$ of cases, respectively. Increased 10-day mortality was associated with severe sepsis, septic shock, increasing age, and any focus other than the urinary tract. Decreased mortality was associated with receiving at least one active antibiotic within the first 48 hours. Intervention of antimicrobial management team during the acute phase of BSI was associated with a decreased mortality at day 10 in the overall population and in health care-related BSI.

Conclusion: Optimizing BSI management by increasing rapidity of appropriate treatment initiation may decrease short-term mortality, even in countries with low rate of multidrug-resistant organisms. Early intervention of antimicrobial management team is crucial in terms of mortality. Keywords: mortality, bloodstream infections, antimicrobial management team, communityacquired infection, health care-related infection

\section{Introduction}

In Europe, the estimated annual number of bloodstream infection (BSI) episodes is circa 1.2 million per year. ${ }^{1}$ The annual number of deaths related to BSI is estimated to range from 157,750 to $2,763,181$. Increased mortality is not only associated with nosocomial BSI, but also with community-acquired BSI under certain circumstances in intensive care unit patients as well as in the inpatient population as a whole. ${ }^{2-4}$

Furthermore, even if BSI management has been suggested as a performance indicator for antimicrobial management programs in health care facilities (HCF), impact of initial management remains highly discussed. More precisely, the role of empirical therapy, time to first active treatment, and also the role of antimicrobial management team (AMT) to drive initial treatment remain highly discussed in terms of mortality. ${ }^{5-8}$ However, this initial management is becoming even more complex with the increasing 
bacterial resistance to antibiotics and remains a challenge that has been particularly demonstrated in specific populations. ${ }^{9,10}$ On one hand, inappropriate initial antibiotic regimen has been related to poor outcome, especially for patients with severe sepsis or septic shock. ${ }^{11}$ On the other hand, inappropriate use of large-spectrum antibiotics leads to unnecessary antibiotic exposure and to a high risk of selecting drug-resistant microorganisms.

Therefore, we conducted a survey focused on the early management of BSI in French HCF. We sought to evaluate its impact on overall, hospital-acquired, and not hospitalacquired BSI short-term mortality.

\section{Patients and methods \\ Setting}

This prospective, observational, multicenter cohort survey was conducted over a period of 1 month in each center between November 2014 and February 2015 among HCF from the "Surveillance de la Prescription des Antibiotiques" (Surveillance of Prescribed Antibiotics) network. ${ }^{12}$ The study protocol was derived from a previous regional survey. ${ }^{13}$ The study was approved by the Tourcoing Hospital Ethics Committee, 16/09/2011. As per the French law for an observational study, patient informed consent was not required (Art L-1121).

All consecutive patients with positive blood cultures during a 1-month period were included. Case ascertainment was done through the microbiology laboratory in association with the clinician belonging to the AMT. AMT of each $\mathrm{HCF}$ audited the management of each episode of BSI. Coagulase-negative staphylococci and other common commensal species were considered as probable contaminants and excluded from the analysis if the organism was isolated from a single set of blood cultures and the local AMT considered the result as a contamination. If patients declared multiple events of bacteremia during the study, only the first episode was included in the survey. Individuals dying the day blood culture was taken were excluded from the analysis, as well as those discharged early to home or transferred early to another medical center (before 72 hours), considering that before this time, antibiotic management could not be fully completed in the same hospital.

Identification and antibiotic susceptibility tests (ASTs) of each microorganism were performed locally in compliance with the European Committee on Antimicrobial Susceptibility Testing 2014. ${ }^{14}$

Data included demographics, pathogens and their susceptibility patterns, portal of entry, hospitalization department, antimicrobial regimens, time to first active antimicrobial after blood culture was taken, intervention of the AMT, and outcome. The beta-lactams allergy and chronic renal failure declared by patients were also recorded. Severity was assessed as the presence of severe sepsis or septic shock at BSI diagnosis. Secondary septic localizations were defined as endocarditis and/or the presence of abscess(es) not considered as the portal of entry. Data were collected on a standardized paper form and electronic data entry was performed locally.

\section{Definitions}

Unless specified, the term "blood stream infection" is used as generic for either bacteremia or fungemia. BSIs were classified as hospital acquired if the first positive blood culture was drawn $>48$ hours after admission to the hospital and community acquired if drawn $\leq 48$ hours after admission. BSIs affecting individuals living in a long-term care facility, under a home hospitalization regimen, in patients with chronic hemodialysis, or in those reporting febrile neutropenia episode following chemotherapy were considered as "other health care-associated BSI". We associated this last group to "hospital-acquired BSI" group to form the "health care-associated BSI" group.

Multidrug-resistant organisms (MDROs) include Enterobacteriaceae producing extended-spectrum beta-lactamases or carbapenemases, methicillin-resistant Staphylococcus aureus (MRSA), glycopeptide-resistant enterococci, betalactam-resistant streptococci, and ceftazidime- or imipenemresistant non-fermenting bacteria.

Patients with at least one organ dysfunction according to Bone's criteria were considered having severe sepsis if they did not require vasoactive drug, and with septic shock if vasoactive drugs were used. ${ }^{15}$ Patients without organ dysfunction were classified as nonsevere.

Empirical treatment was defined as a treatment initiated before gram stain result availability. Ongoing treatment after availability of AST results was considered as "targeted therapy". Empirical and targeted antimicrobial treatment regimens were analyzed considering antibiotic susceptibility patterns and drug pharmacokinetics. Therapy was considered appropriate if patients had received at least one systemic drug to which (all) the organism(s) was (were) susceptible, with appropriate dosage, adequate route of administration, and tissue distribution.

Complications of BSI are secondary infection, abscess, and endocarditis. 


\section{Analysis}

Continuous variables are expressed as means or medians and ranges. Categorical variables are expressed as proportions. Statistical analyses were carried out to determine factors associated with all-cause 10-day mortality. First, univariable and multivariable logistic regression were performed for the whole population and for two subgroups defined as health care-related BSI and community-acquired BSI. Multivariable analysis was performed starting with all appropriate variables with a $P<0.20$ in the univariable analysis. Final multivariable models were selected using backward elimination of variables with $P>0.05$ and retaining the variables of clinical interest, such as appropriate antibiotic at day 1 or at any time, depending on the group analyzed. A sensitivity analysis including individuals who died at day 1 and who were discharged early was also performed. Statistical analyses were performed using R software version 3.3.3 (http://www.R-project.org).

\section{Results \\ Settings and patients}

During the 4-month study period, 121 hospitals (20 university hospitals, 62 public hospitals, 3 not-for-profit cancer centers, 27 private $\mathrm{HCF}$, and 9 rehabilitation/long-term care facilities) were involved. Median size of participating hospitals was 265 (112-450) acute care beds. Median number of inclusions per hospital was 17(8-30). Overall, data from 2,197 patients with BSI were collected. One $(<0.1 \%)$ individual died on day 1 of BSI management, 147 (7\%) were transferred or discharged to home early before 48 hours, and 97 (4\%) were discharged between day 3 and day 10 and lost to follow-up. Most of these patients suffered from community-acquired BSI (64/97 [66\%]) and had baseline characteristic similar to individuals included in the survey. This resulted in 1,952 (89\%) individuals with complete data (Figure 1). Patients were hospitalized in the following departments: medicine $(n=1,052$, $54 \%)$, surgery $(\mathrm{n}=259,13 \%)$, intensive care $(\mathrm{n}=254,13 \%)$, oncology-hematology $(n=182,9 \%)$, geriatrics $(n=139,8 \%)$, and gynecology/obstetrics/pediatrics $(n=66,3 \%)$.

The median age was 73 years (interquartile range: $60-83$ ). Also, $68 \%, 22 \%$, and $10 \%$ of the patients were considered as nonsevere, with severe sepsis, and with septic shock, respectively. The median time of follow-up was 19 days (interquartile range: 14-30). Secondary septic localizations were reported in 392 patients (20\%), including 63 endocarditis cases $(3 \%)$. Details on patient characteristics are presented in Table 1.

Within the 10-day follow-up, 197 (10\%) patients died.

\section{Bloodstream infection}

Of 1,952 BSIs, 763 were considered hospital acquired (39\%), 313 were other health care-associated BSIs (16\%), and 876 were community-acquired BSIs (45\%). The most frequent portal of entry was the urinary tract $(n=522 / 1,952,27 \%)$ for all BSIs and in community-acquired BSI ( $n=235 / 867$, $33 \%)$. Intravenous catheter was the most common portal of entry in health care-related BSI ( $n=366 / 1,085,34 \%)$, as shown in Table 1. MDROs were associated with BSI in 10\% of cases $(n=173 / 1,779)$ and were more frequent in health care-associated infection compared to community-acquired infection ( $13 \%$ vs $6 \%, P<0.001)$. Among 2,077 isolated strains, Escherichia coli $(\mathrm{n}=580,28 \%)$ and $S$. aureus $(\mathrm{n}=358$, $17 \%$ ) were the most frequent microorganisms (Table 2). A total of $202(9.7 \%)$ bacterial isolates were MDROs, including $122(59 \%)$ extended-spectrum beta-lactamases and 67 MRSA (33\%). These resistant strains were mostly found in health care-related BSI $(12 \%[144 / 1,175]$ vs $6 \%$ [58/902] in health care-related vs community-acquired BSI, respectively; $P<0.001$; Table 2). Polymicrobial BSI was observed in 110 $(6 \%)$ cases.

\section{Management of BSI}

Overall, 1,814 (93\%) patients received at least one active drug when considering the AST pattern. Empirical therapy was considered appropriate in 1,191 (61\%) cases. Adequate therapy was started within the first 24 hours for 883 individuals (45\%) and within the first 48 hours for 1,610 (82\%) individuals, respectively (Figure 1). Appropriate treatment starting within the first 48 hours was more frequent for "communityacquired" than for "health care-related" BSI ( $89 \%$ vs $77 \%$, respectively; $P<0.001)$. Targeted therapy was also more likely to be adequate for "community-acquired" than for "health care-related" BSI $(96 \%$ vs $92 \% ; P<0.001)$. In the subset $(n=1,764)$ of cases with data available for hourly timing of blood culture and antibiotic administration, the mean delay from the time when blood samples were taken to prescription of an active drug was $24.4 \pm 36$ hours (median 12 hours)

Empirical combination therapy was used in $43 \%$ of cases. It was more frequent in the case of patients with severe sepsis/ septic shock than in other cases $(57 \%$ vs $37 \% ; P<0.001)$.

The three most frequently used drugs for empirical therapy were ceftriaxone $(n=821,16.3 \%)$, amoxicillin/ clavulanic acid $(n=462,9.2 \%)$, and gentamicin $(n=436$, $8.7 \%)$. For targeted therapy, the drugs used were ceftriaxone $(\mathrm{n}=457,11.9 \%)$, amoxicillin/clavulanic acid $(\mathrm{n}=311,8.1 \%)$, and ofloxacin $(\mathrm{n}=307,8 \%)$. 


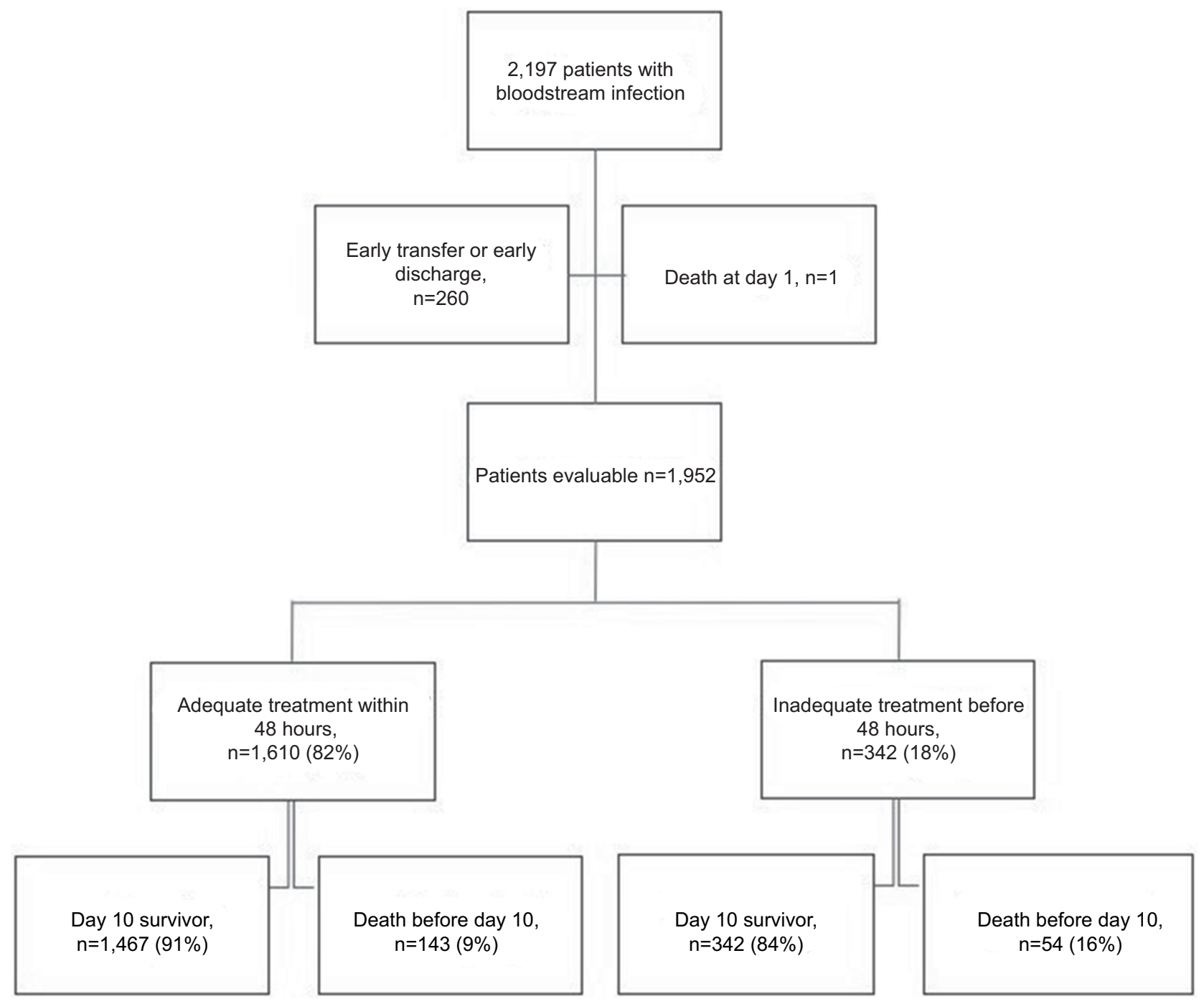

Figure I Flowchart of antimicrobial therapy regimens and outcome.

\section{Ten-day mortality}

In multivariable analysis (Table 3), severe sepsis, septic shock, allergy to beta-lactam, age over 72 years, a portal of entry other than the urinary tract, and initiation of efficient treatment over the first 48 hours remained independently associated with 10-day mortality. Factors associated with lower mortality were chronic renal failure, intervention by an AMT, and BSI due to E. coli, another Enterobacteriaceae, or another gram-positive coccus compared to $S$. aureus. The sensitivity analysis including patients with early discharge or who died on day 1 did not change these results significantly (data not shown).

\section{Ten-day mortality: subgroup analysis}

In patients with health care-associated BSI, intervention of the AMT, an E. coli, another Enterobacteriaceae or another gram-positive coccus BSI compared to $S$. aureus and chronic renal failure BSI were independently associated with decreased mortality. Severe sepsis, septic shock, a digestive tract infection, an unknown portal of entry, pneumoniae, age over 72 years, and treatment initiation after 48 hours were independently associated with mortality (Table 3 ). In case of patients with not community-acquired BSI, time to efficient treatment was also positively associated with mortality when started after 48 hours (Table 3 ).

\section{Discussion}

This work was an opportunity to look at the management of both community-acquired and health care-related BSI in the same time lapse, using the same methodology. This makes us able to define the impact on mortality of BSI initial management for overall BSI and for the two subgroups. This study was also the opportunity to estimate MDRO prevalence associated with BSI, which remains low in France. 


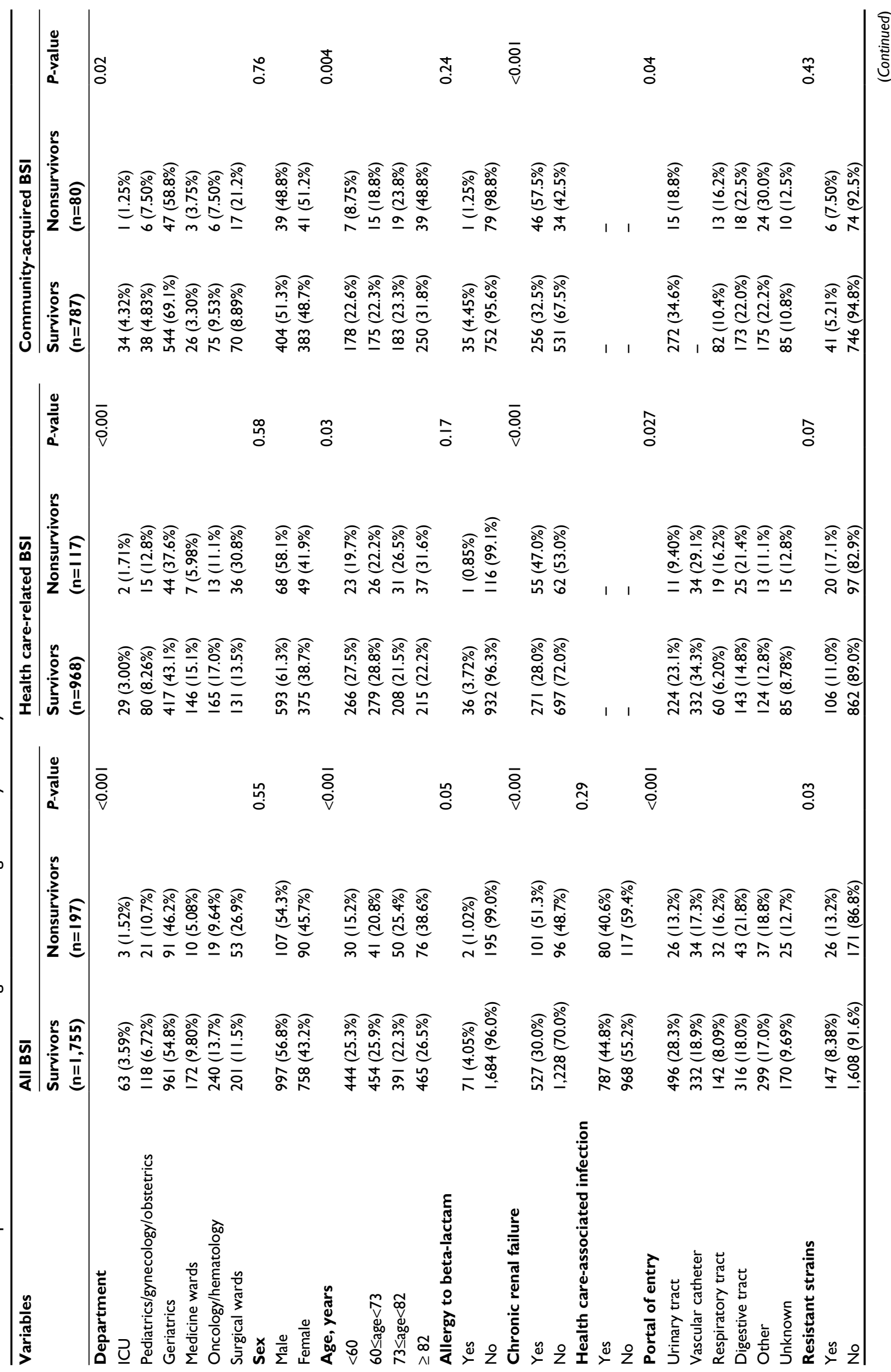




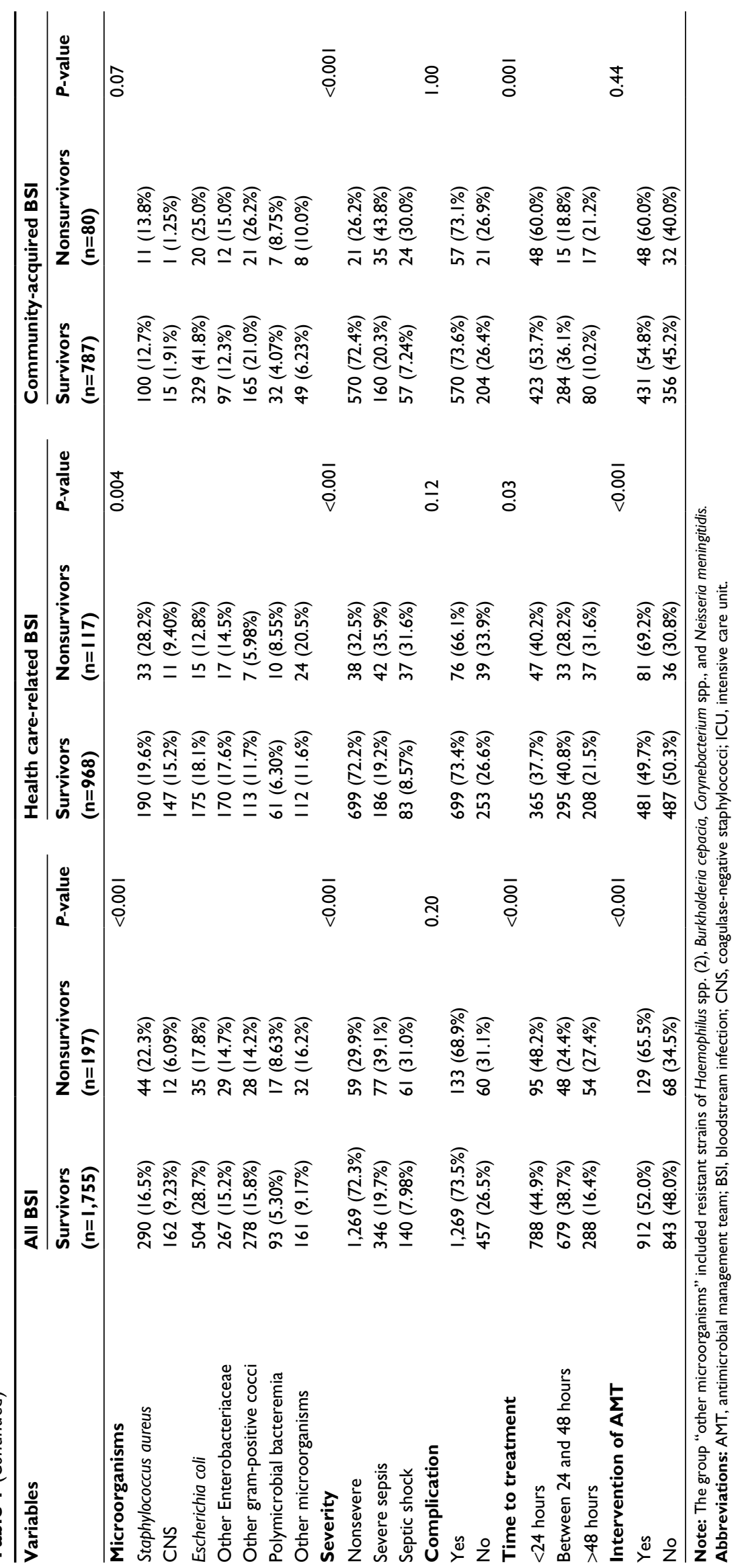


Table 2 Bacterial species and MDR from I,952 bloodstream infections in 121 French hospitals in 2014-2015

\begin{tabular}{|c|c|c|c|c|c|c|}
\hline \multirow[t]{2}{*}{ Microorganisms } & \multicolumn{2}{|l|}{ Overall BSI } & \multicolumn{2}{|c|}{ Health care-related infection } & \multicolumn{2}{|c|}{ Community-acquired BSI } \\
\hline & Not MDR & MDR & Not MDR & MDR & Not MDR & MDR \\
\hline Staphylococcus aureus & $291(15.4 \%)$ & 67 (33.2\%) & $188(18.2 \%)$ & $55(38.2 \%)$ & $103(12.3 \%)$ & $12(20.7 \%)$ \\
\hline CNS & 201 (11.1\%) & $0(0 \%)$ & $184(17.8 \%)$ & $0(0 \%)$ & $17(2.0 \%)$ & $0(0 \%)$ \\
\hline Streptococcus sp. & 134 (7.1\%) & $3(1.5 \%)$ & $38(3.7 \%)$ & I $(0.7 \%)$ & $96(11.1 \%)$ & $2(3.4 \%)$ \\
\hline Streptococcus pneumoniae & $72(4.0 \%)$ & $\mathrm{I}(0.5 \%)$ & $10(1.0 \%)$ & $0(0.0 \%)$ & $62(7.4 \%)$ & $\mathrm{I}(\mathrm{I} .7 \%)$ \\
\hline Enterococcus sp. & 134 (7.1\%) & $0(0.0 \%)$ & $99(9.6 \%)$ & $0(0.0 \%)$ & $35(4.2 \%)$ & $0(0.0 \%)$ \\
\hline Escherichia coli & $516(27.3 \%)$ & $64(31.8 \%)$ & $172(16.7 \%)$ & $33(22.9 \%)$ & $344(40.8 \%)$ & 31 (53.4\%) \\
\hline Other Enterobacteriaceae & $259(13.7 \%)$ & $58(28.7 \%)$ & $169(16.4 \%)$ & 49 (34.0\%) & $90(10.6 \%)$ & $9(15.5 \%)$ \\
\hline Pseudomonas aeruginosa & $72(3.8 \%)$ & $3(1.5 \%)$ & $62(6.0 \%)$ & $3(2.1 \%)$ & $10(1.2 \%)$ & $0(0.0 \%)$ \\
\hline Other non-fermenting & $18(1.0 \%)$ & $0(0.0 \%)$ & $15(1.6 \%)$ & $0(0.0 \%)$ & $3(0.3 \%)$ & $0(0.0 \%)$ \\
\hline Salmonella sp. & 14 (0.8\%) & $0(0.0 \%)$ & $4(0.4 \%)$ & $0(0.0 \%)$ & $10(1.19 \%)$ & $0(0.0 \%)$ \\
\hline Anaerobes & $68(3.6 \%)$ & I $(0.5 \%)$ & $42(4.1 \%)$ & $0(0.0 \%)$ & $26(3.1 \%)$ & I (I.7\%) \\
\hline Candida sp. & 37 (1.9\%) & $0(0.0 \%)$ & $30(3.3 \%)$ & $0(0.0 \%)$ & $7(0.8 \%)$ & $0(0.0 \%)$ \\
\hline Other & $59(3.1 \%)$ & $5(2.5 \%)$ & $18(1.7 \%)$ & $3(2.1 \%)$ & 41 (4.9\%) & $2(3.4 \%)$ \\
\hline Total & I,875 (100\%) & $202(100 \%)$ & I,03। (I00\%) & 144 (100\%) & 844 (100\%) & $58(100 \%)$ \\
\hline
\end{tabular}

Abbreviations: BSI, bloodstream infection; CNS, Coagulase-negative staphulococci; MDR, multidrug resistance.

Table 3 Results of multivariate analysis of items associated with 10-day mortality for all BSIs, hospital-acquired BSI, and not hospitalacquired BSI

\begin{tabular}{|c|c|c|c|c|c|c|}
\hline \multirow[t]{2}{*}{ Variables } & \multicolumn{2}{|l|}{ All BSIs } & \multicolumn{2}{|c|}{ Health care-related BSI } & \multicolumn{2}{|c|}{ Community-acquired BSI } \\
\hline & OR $(95 \% \mathrm{Cl})$ & $P$-value & OR $(95 \% \mathrm{CI})$ & $P$-value & OR (95\% Cl) & $P$-value \\
\hline Sex & $1.43(1.02-1.99)$ & 0.03 & & & $1.64(0.98-2.79)$ & 0.06 \\
\hline \multicolumn{7}{|c|}{ Age (reference: < 60 years) } \\
\hline $60 \leq$ age $<72$ & $1.27(0.75-2.17)$ & 0.38 & $1.07(0.56-2.04)$ & 0.84 & $2.24(0.85-6.4)$ & 0.11 \\
\hline $72 \leq$ age $<82$ & $2.1(1.25-3.57)$ & 0.005 & $1.9(1-3.61)$ & 0.04 & $3.16(1.25-8.8)$ & 0.02 \\
\hline$\geq 82$ & $2.56(1.56-4.29)$ & $<0.001$ & $2.27(1.19-4.32)$ & 0.01 & $4.57(1.94-12.24)$ & 0.001 \\
\hline Chronic renal failure & $0.61(0.43-0.85)$ & 0.003 & $0.61(0.39-0.96)$ & 0.03 & $0.55(0.32-0.93)$ & 0.03 \\
\hline Allergy to beta-lactam & $4.69(1.35-29.72)$ & 0.04 & $7.12(0.92-55.21)$ & 0.06 & & \\
\hline \multicolumn{7}{|c|}{ Focus (reference: urinary tract) } \\
\hline Vascular catheter & $1.97(1.02-3.82)$ & 0.04 & $1.91(0.84-4.34)$ & 0.12 & - & \\
\hline Pneumonia & $3.32(1.71-6.5)$ & $<0.001$ & $4.83(1.93-12.09)$ & $<0.001$ & $2.75(1.15-6.55)$ & 0.02 \\
\hline Digestive tract & $2.25(1.28-3.99)$ & 0.005 & $3.57(1.56-8.15)$ & 0.002 & I.7I (0.79-3.75) & 0.18 \\
\hline Other & $2.11(1.1-4.1)$ & 0.03 & I.5I (0.57-4) & 0.41 & $3.29(1.58-7.08)$ & 0.002 \\
\hline Unknown & $2.53(1.29-4.95)$ & 0.006 & $3.31(1.31-8.33)$ & 0.01 & $2.14(0.83-5.34)$ & 0.11 \\
\hline \multicolumn{7}{|c|}{ Severity (reference: nonsevere) } \\
\hline Severe sepsis & $4.31(2.94-6.35)$ & $<0.001$ & $4.15(2.48-6.96)$ & $<0.001$ & $5.47(3.02-10.14)$ & $<0.001$ \\
\hline Septic shock & $9.45(6.07-14.77)$ & $<0.001$ & $8.34(4.67-\mid 4.91)$ & $<0.001$ & II.22 (5.57-22.93) & $<0.001$ \\
\hline \multicolumn{7}{|c|}{ Microorganism (reference: Staphylococcus aureus) } \\
\hline CNS & $0.45(0.21-0.94)$ & 0.04 & $0.37(0.17-0.84)$ & 0.026 & & \\
\hline Escherichia coli & $0.45(0.24-0.83)$ & 0.01 & $0.33(0.15-0.76)$ & 0.01 & & \\
\hline Other Enterobacteriaceae & $0.54(0.29-0.98)$ & 0.04 & $0.36(0.17-0.76)$ & 0.008 & & \\
\hline Other gram-positive cocci & $0.45(0.25-0.8)$ & 0.007 & $0.19(0.07-0.5)$ & $<0.001$ & & \\
\hline Polymicrobial bacteremia & $0.85(0.4-1.73)$ & 0.65 & $0.58(0.23-1.43)$ & 0.24 & & \\
\hline Other microorganisms & $0.76(0.42-1.38)$ & 0.37 & $0.55(0.27-1.13)$ & 0.10 & & \\
\hline \multicolumn{7}{|c|}{ Time to treatment (reference: $<24$ hours) } \\
\hline Between 24 and 48 hours & $0.79(0.53-1.17)$ & 0.23 & $0.95(0.56-1.6)$ & 0.84 & $0.57(0.29-1.08)$ & 0.09 \\
\hline$>48$ hours & $1.91(1.24-2.92)$ & 0.003 & $1.87(1.08-3.26)$ & 0.03 & $2.38(1.17-4.77)$ & 0.02 \\
\hline Intervention of AMT & $0.58(0.4 \mathrm{I}-0.82)$ & 0.002 & $0.42(0.26-0.66)$ & $<0.001$ & & \\
\hline
\end{tabular}

Abbreviations: AMT, antimicrobial management team; BSI, bloodstream infection; CNS, coagulase-negative staphylococci; OR, odds ratio.

First, we found that the involvement of antibiotics management team in BSI management was associated with decreased mortality, especially in hospital-acquired infection. Interestingly, this variable remained significant independently of the antibiotic regimen appropriateness. This might be explained by the fact that the role of the AMT is also to manage dosage, side effect, drug interaction, and follow-up. It is well-known that AMT interventions increase the rate of 
appropriate treatment, decrease the use of broad-spectrum antibiotics, and reduce the costs of antimicrobial treatment without increasing death. ${ }^{1,5,16-18}$ While the overall positive impact of AMT on mortality is only supported by low level of scientific evidence, it has, nevertheless, been well described for specific drug regimen or infection. ${ }^{8}$ Our prospective study supports that AMT intervention as a bedside consultation, as is largely done by AMT in France, seems to be efficient on mortality. ${ }^{8,19}$

Second, we confirmed that time to appropriate treatment is a key factor of mortality, independently of severity, portal of entry, and microorganisms, whatever the infection was, acquired in community or health care related. The impact of delayed effective antimicrobial therapy on mortality remains a key concern in BSI with a large number of studies varying in terms of methodology, patient recruitment, and microorganism involved. ${ }^{7,19-26}$ In any case, in critically ill patients, treatment needs to be started within the first 2 hours of clinical management. ${ }^{26-28}$ In our study, patients received an active drug quite early (median time 12 hours), either as empirical therapy or with a rapid adjustment following the first report of a positive blood culture and gram stain by the microbiology laboratory. Our results associated with literature cited above argue for improving appropriate empirical treatment and for rapid diagnostic procedures when clinical symptoms of infection occur, especially in case of hospital-acquired infection. This underlines the need for not only regular updates of empirical treatment strategies, which need to be adjusted to the local microbiological environment, but also rapid microbial identification as it has already been suggested. ${ }^{29,30}$

Third, we confirmed a low prevalence of multidrug resistance concentrated in hospital-acquired BSI. The proportion of resistant $E$. coli and MRSA is similar to the result of the most recent European study and of a recent English survey on third-generation cephalosporin resistance. ${ }^{31,32}$ Interestingly, even with this low prevalence of MDRO, only two-thirds of empirical treatments were active against the isolated pathogens, mostly in community-acquired BSI as demonstrated in a previous study on gram-negative BSI. ${ }^{6}$ This not only highlights the need for an efficient antimicrobial resistance surveillance system, but also suggests conducting studies to understand this high rate of inappropriate initial management.

Fourth, the protective effect of chronic renal failure is surprising. Our data suggest this could be associated to drug overexposure with the use of non-adjusted dosages. This might suggest higher dosages could be more effective at the acute phase of the infection. In severe sepsis or septic shock patients, the increased volume of distribution leads many intensive care teams to use high dosages. This might also be useful for patients with less-severe clinical presentation with factors associated with higher BSI mortality.

Finally, our study suffers from limitations. First, we did not have detailed information on patients' comorbidities and characteristics at BSI diagnosis. However, we believe the available data on sex, age, BSI origin, sepsis severity, and chronic renal failure provide sufficient information to evaluate patient severity. Our model did not take into account time-dependent variables such as length of stay within the hospital before BSI happened, and we did not consider time to treatment as a time-dependent variable. This was decided to be consistent with previous literature and because of the design of the survey which aimed at investigating short-term mortality. ${ }^{6}$ Furthermore, correct antibiotic regimen was started before 48 hours for $>80 \%$ of patients, suggesting that few biases could be introduced due to events happening between blood culture and appropriate treatment. Last, this study was designed to evaluate 10-day mortality, which can be considered as death during the acute phase of BSI. We considered that long-term mortality needs more information than patient characteristics at the time of the onset and time-dependent variable needs to be introduced in the model. However, we also compared patients with in-hospital death before day 28 to patients discharged at any time or still alive at day 28 . This analysis needed to be conducted with care, but gave similar results except that hospital acquisition became a risk factor of death and effect of antibiotics stewardship team was nonsignificant for the overall population.

BSIs need to have appropriate treatment started at least within the first 48 hours. AMT intervention has an impact on short-term mortality. Further investigation needs to be conducted to optimize probabilistic treatment and evaluate early AMT involvement in BSI management with a view to prevent early death and provide appropriate initial coverage without using an unnecessary wide spectrum of antibiotics.

\section{Acknowledgments}

The authors are thankful to Sandrine Clement for building the electronic survey questionnaire and managing the database. The Société de pathologie Infectieuse de Langue Française (SPILF) provided the financial support for data management. The Surveillance of Prescribed Antibiotics bacteremia group investigators are shown as hospital and city (name): CH Bourg-en-Bresse (P Granier), CH Soissons (D Line), CH Vichy (F Gourdon), Clinique du Vivarais, Aubenas (M Soulerin), CH Charleville Mézières (L Thiriet), CH Troyes (S Pavel), Hôpital Européen, Marseille (N Beni-Chougrane), 
Clinique Chirurgicale, Martigues (L Richard Riou), Hôpital Prive Beauregard, Marseille (ME Cornesse), CH Saint Flour (W Ghys), CH Aurillac (I Masse-Chabredier), Hôpital Privé Guillaume de Varye, Saint-Doulchard (R Sallah), CHU Dijon (A Lefebvre), CH Semur-En-Auxois (ML Michon Sarem), CHU Besancon (X Bertrand), CH Chartres (J Darasteanu), CHU Brest (S Jaffuel), CH Cornouaille (JP Talarmin), CHU Nimes (C Lechiche), CHU Toulouse (B Marchou), CH Auch (S Arista), MSP.Bx, Talence (B Decouard), Clinique Tivoli, Bordeaux (P Ribelle), CH Béziers (S Hubiche), Clinique du Millénaire, Montpellier (P Andre), CH Saint Malo (M Dupont), Polyclinique St Privat, Boujan-sur-Libron (L Safon), CHIC Amboise-Chateaurenault (B Cattier), $\mathrm{CH}$ Voiron (AS Michalski), CHU Grenoble (P Pavese), $\mathrm{CH}$ Pays de Gier (F Bergheau), CHU Saint-Etienne (C Cazorla), Nouvelles Cliniques Nantaises et Centre Catherine de Sienne, Nantes (O Grossi), CH Gien (B Rousseau), CHU Angers (S Rehaiem), CHU Reims (V Vernet Garnier), Polyclinique Courlancy, Reims (C Vallet), CH Pont A Mousson (M Paulus), CHU Nancy (S Henard), CH Sarrebourg (H Jouin), HIA Brest (L Karkowski), EPDS Gorze (A De Mouzon), CH Douai (C Debruille), PolycliniqueVauban, Valenciennes (L Marta), CH Cambrai (B Kairis), CH Maubeuge ( $\mathrm{T}$ Levent), $\mathrm{CH}$ Tourcoing (S Alfandari), $\mathrm{CH}$ Roubaix (C Laurans), CH Armentières (P Saint-Leger), CH Hazebrouck (G Baussant), CHIC Alencon-Mamers (J Delhomme), CH Béthune (F Vuotto), CH Lens (H Bazus), $\mathrm{CH}$ Arras (C Vandenbussche), $\mathrm{CH}$ Henin Beaumont (C Domrault-Tanguy), CHU Clermont-Ferrand (O Baud), $\mathrm{CH}$ Lannemezan (MT Banos), CH Perpignan (A Eden), Clinique Saint-Pierre, Perpignan (O Pantaloni), Clinique Adassa, Strasbourg (A Sauer), Hôpital du Neuenberg, Ingwiller (L Hennequin), CHU Strasbourg (N Lefebvre), Clinique des Diaconesses, Strasbourg (V Duperrier), Cliniques Diaconat Fonderie et Roosevelt, Mulhouse (M Guthwasser), Centre Léon Bérard, Lyon (C Fuhrmann), Centre Revel, Saint Maurice sur Dargoire (F Greil), HIA Lyon (P Gerome), Cliniques Mutualistes, Lyon (B Gravagna), CH Macon (J Machon), Hôpital La Clayette (V Talpin), CH Chalon S/ Saone (J Coutet), CHI Albertville-Moutiers, CH Bourg St Maurice, SSR Tresserve (G Manquat), Medipole de Savoie, Challes-les-Eaux (P Monteil), CH Annecy (V Vitrat), CHU Pitié-Salpêtrière, Paris (J Robert), CHU Cochin, Paris (D Sroussi), CHU Bichat, Paris (X Lescure), Institut Montsouris, Paris (JY Nizou), Institut Curie, Paris (D Vanjak), CH Dieppe (S Edouard), CH Coulommiers (G Nicolaos), Institut Médical, Serris (L Seng), CH Versailles (A Greder Belan), Polyclinique lesFleurs, Ollioules (PM Roger), $\mathrm{CH}$
Carpentras (V Chaix), CH Orange (S Comparot), CH Vaison la Romaine (V Chaix), Clinique Rhône Durance, Avignon (C Bertrand), Polyclinique Synergia, Carpentras (S Pascal), CHD Vendée, LaRoche-sur-Yon (T Guimard), CHU Poitiers (F Roblot), CH Sens (C Guignabert), CH Belfort (L Toko Tchuindzie), CH Corbeil-Essonnes (A Chabrol), CH Bligny (V Herve), Hôpital Foch, Suresnes (P Lesprit), Centre Chir. M. Lannelongue, Plessis-Robinson (M Keirle), CHU Ambroise Paré, Boulogne (F Espinasse), Hôpital Antoine Béclère, Clamart (F Doucet-Populaire), Hôpital Beaujon, Clichy (A Lefort), Hôpital Louis Mourier, Colombes ( $G$ Marcade), Hôpital Raymond Poincaré, Garches (A Dinh), Hôpital Corentin Celton, Issy-Les-Moulineaux (V Moulin), HIAClamart (C Mac Nab), Hôpital Privé, Antony (J Livartowski), CH Aulnay (AL Lecapitaine), Institut Gustave Roussy, Villejuif (F Netzer), CHU Mondor, Créteil (R Lepeule), Hôpital Charles Foix, Ivry-sur-Seine (L DrieuxRouzet), Hôpital de Bicêtre (L Escaut), Hôpital Emile Roux, Limeil Brevannes (A Akpabie), HIA St Mandé (C Rapp), Hôpital Privé, Thiais (G Demelin), Hôpital L'Isle-Adam (M Cliquennois), CH St Paul (A Lignereux), CH Bastia (M Bourleaud), CHU de Martinique (B Roze).

\section{Disclosure}

The authors report no conflicts of interest in this work.

\section{References}

1. Goto M, Al-Hasan MN. Overall burden of bloodstream infection and nosocomial bloodstream infection in North America and Europe. Clin Microbiol Infect. 2013;19(6):501-509.

2. Lambert ML, Suetens C, Savey A, et al. Clinical outcomes of healthcare-associated infections and antimicrobial resistance in patients admitted to European intensive-care units: a cohort study. Lancet Infect Dis. 2011;11(1):30-38.

3. Prowle JR, Echeverri JE, Ligabo EV, et al. Acquired bloodstream infection in the intensive care unit: incidence and attributable mortality. Crit Care. 2011;15(2):R100.

4. Diekema DJ, Beekmann SE, Chapin KC, Morel KA, Munson E, Doern GV. Epidemiology and outcome of nosocomial and community-onset bloodstream infection. J Clin Microbiol. 2003;41(8):3655-3660.

5. Society for Healthcare Epidemiology of America, Infectious Diseases Society of America, Pediatric Infectious Diseases Society. Policy statement on antimicrobial stewardship by the Society for Healthcare Epidemiology of America (SHEA), the Infectious Diseases Society of America (IDSA), and the Pediatric Infectious Diseases Society (PIDS). Infect Control Hosp Epidemiol. 2012;33(4):322-327.

6. Fitzpatrick JM, Biswas JS, Edgeworth JD, et al. Gram-negative bacteraemia; a multi-centre prospective evaluation of empiric antibiotic therapy and outcome in English acute hospitals. Clini Microbiol Infect. 2016;22(3):244-251.

7. Lodise TP, Patel N, Kwa A, et al. Predictors of 30-day mortality among patients with Pseudomonas aeruginosa bloodstream infections: impact of delayed appropriate antibiotic selection. Antimicrob Agents Chemother. 2007;51(10):3510-3515.

8. Schuts EC, Hulscher M, Mouton JW, et al. Current evidence on hospital antimicrobial stewardship objectives: a systematic review and metaanalysis. Lancet Infect Dis. 2016;16(7):847-856. 
9. Irwin AD, Drew RJ, Marshall P, et al. Etiology of childhood bacteremia and timely antibiotics administration in the emergency department. Pediatrics. 2015;135(4):635-642.

10. Gudiol C, Bodro M, Simonetti A, et al. Changing aetiology, clinical features, antimicrobial resistance, and outcomes of bloodstream infection in neutropenic cancer patients. Clin Microbiol Infect. 2013;19(5):474-479.

11. Marquet K, Liesenborgs A, Bergs J, Vleugels A, Claes N. Incidence and outcome of inappropriate in-hospital empiric antibiotics for severe infection: a systematic review and meta-analysis. Crit Care. 2015;19(1):63. Available from: https://www-ncbi-nlm-nih-gov.gate2. inist.fr/pmc/articles/PMC4358713/. Accessed February 10, 2018.

12. Alfandari S, Robert J, Péan $Y$, et al. Antibiotic use and good practice in 314 French hospitals: the 2010 SPA2 prevalence study. Med Mal Infect. 2015;45(11-12):475-480.

13. Alfandari S, Cabaret P, Nguyen S, et al. Evaluating the management of 493 patients presenting with bacteremia in 23 northern French hospitals. Med Mal Infect. 2016;46(4):194-199.

14. The European Committee on Antimicrobial Susceptibility Testing. Breakpoint tables for interpretation of MICs and zone diameters. Version 4.0, 2014. Available from: http://www.eucast.org/fileadmin/src/media/ PDFs/EUCAST_files/Breakpoint_tables/Breakpoint_table_v_4.0.pdf. Accessed February 8, 2018.

15. Bone RC, Balk RA, Cerra FB, et al. Definitions for sepsis and organ failure and guidelines for the use of innovative therapies in sepsis. The ACCP/SCCM Consensus Conference Committee. American College of Chest Physicians/Society of Critical Care Medicine. Chest. 1992;101(6):1644-1655.

16. Dyar OJ, Tebano G, Pulcini C, ESGAP (ESCMID Study Group for Antimicrobial stewardshiP). Managing responsible antimicrobial use: perspectives across the healthcare system. Clin Microbiol Infect. 2017;23(7):441-447.

17. Demoré B, Humbert P, Boschetti E, et al. Evaluation of effects of an operational multidisciplinary team on antibiotic use in the medium to long term at a French university hospital. Int J Clin Pharm. 2017;39(5): 1061-1069.

18. Seah VXF, Ong RYL, Lim ASY, Chong CY, Tan NWH, Thoon KC. Impact of a carbapenem antimicrobial stewardship program on patient outcomes. Antimicrob Agents Chemother. 2017;61(9):e00736-17.

19. Tang G, Huang L, Zong Z. Impact of infectious disease consultation on clinical management and outcome of patients with bloodstream infection: a retrospective cohort study. Sci Rep. 2017;7(1):12898.

20. Vazquez-Guillamet C, Scolari M, Zilberberg MD, Shorr AF, Micek ST, Kollef M. Using the number needed to treat to assess appropriate antimicrobial therapy as a determinant of outcome in severe sepsis and septic shock. Crit Care Med. 2014;42(11):2342-2349.
21. Zasowski EJ, Claeys KC, Lagnf AM, Davis SL, Rybak MJ. Time is of the essence: the impact of delayed antibiotic therapy on patient outcomes in hospital-onset enterococcal bloodstream infections. Clin Infect Dis. 2016;62(10):1242-1250.

22. Yoon YK, Park DW, Sohn JW, et al. Effects of inappropriate empirical antibiotic therapy on mortality in patients with healthcare-associated methicillin-resistant Staphylococcus aureus bacteremia: a propensitymatched analysis. BMC Infect Dis. 2016;16:331.

23. Gradel KO, Jensen US, Schønheyder HC, et al. Impact of appropriate empirical antibiotic treatment on recurrence and mortality in patients with bacteraemia: a population-based cohort study. BMC Infect Dis. 2017;17(1):122

24. Mcgregor JC, Rich SE, Harris AD, et al. A systematic review of the methods used to assess the association between appropriate antibiotic therapy and mortality in bacteremic patients. Clin Infect Dis. 2007;45(3):329-337.

25. Hernández C, Fehér C, Soriano A, et al. Clinical characteristics and outcome of elderly patients with community-onset bacteremia. $J$ Infect. 2015;70(2):135-143.

26. Lee CC, Lee CH, Hong MY, Tang HJ, Ko WC. Timing of appropriate empirical antimicrobial administration and outcome of adults with community-onset bacteremia. Crit Care. 2017;21(1):119.

27. Larché J, Azoulay Élie, Fieux F, et al. Improved survival of critically ill cancer patients with septic shock. Intensive Care Med. 2003;29(10):1688-1695.

28. Gaieski DF, Mikkelsen ME, Band RA, et al. Impact of time to antibiotics on survival in patients with severe sepsis or septic shock in whom early goal-directed therapy was initiated in the emergency department. Crit Care Med. 2010;38(4):1045-1053.

29. Bookstaver PB, Nimmich EB, Smith TJ, et al. Cumulative effect of an antimicrobial stewardship and rapid diagnostic testing bundle on early streamlining of antimicrobial therapy in gram-negative bloodstream infections. Antimicrob Agents Chemother. 2017;61(9): e00189-17.

30. Timbrook TT, Morton JB, Mcconeghy KW, Caffrey AR, Mylonakis E, Laplante KL. The effect of molecular rapid diagnostic testing on clinical outcomes in bloodstream infections: a systematic review and meta-analysis. Clin Infect Dis. 2017;64(1):15-231.

31. Gagliotti C, Balode A, Baquero F, et al. Escherichia coli and Staphylococcus aureus: bad news and good news from the European Antimicrobial Resistance Surveillance Network (EARS-Net, formerly EARSS), 2002 to 2009. Euro Surveill. 2011;16(11):19819.

32. Bou-Antoun S, Davies J, Guy R, Johnson AP, Sheridan EA, Hope RJ. Descriptive epidemiology of Escherichia coli bacteraemia in England, April 2012 to March 2014. Euro Surveill. 2016;21(35).
Infection and Drug Resistance

\section{Publish your work in this journal}

Infection and Drug Resistance is an international, peer-reviewed openaccess journal that focuses on the optimal treatment of infection (bacterial, fungal and viral) and the development and institution of preventive strategies to minimize the development and spread of resistance. The journal is specifically concerned with the epidemiology of antibiotic resistance and the mechanisms of resistance development and diffusion in both hospitals and the community. The manuscript management system is completely online and includes a very quick and fair peerreview system, which is all easy to use. Visit http://www.dovepress.com/ testimonials.php to read real quotes from published authors. 